\title{
Incorporation of proteins and enzymes at different stages of the preparation of calcium phosphate coatings on a degradable substrate by a biomimetic methodology
}

\author{
Helena S. Azevedo ${ }^{\mathrm{a}, \mathrm{b}, *}$, Isabel B. Leonor ${ }^{\mathrm{a}, \mathrm{b}}$, Catarina M. Alves ${ }^{\mathrm{a}, \mathrm{b}}$, Rui L. Reis ${ }^{\mathrm{a}, \mathrm{b}}$ \\ a3B's Research Group, Biomaterials, Biodegradables and Biomimetics, University of Minho, Campus de Gualtar, 4710-057 Braga, Portugal \\ ${ }^{\mathrm{b}}$ Department of Polymer Engineering, University of Minho, Campus de Azurém, 4800-058 Guimarães, Portugal
}

Available online 10 March 2005

\begin{abstract}
In this work, the possibility of incorporating proteins into calcium phosphate (Ca-P) coatings, prepared on the surface of starch polymeric biomaterials by means of a biomimetic route, was investigated. The morphology, chemical composition and crystallinity of Ca$\mathrm{P}$ coatings was assessed and related to the incorporation of the studied biomolecules. For that, bovine serum albumin (BSA) and $\alpha$ amylase were added in concentrations of $1 \mathrm{mg} / \mathrm{ml}$ to simulated body fluid (SBF) solutions, being both added at the nucleation or growth stages of the biomimetic coating process. A biodegradable blend of corn starch/ethylene vinyl alcohol (SEVA-C) was used as substrate and bioactive glass (45S5 Bioglass ${ }^{\circledR}$ ) was used as the nucleating agent. The obtained Ca-P coatings were characterised by scanning electron microscopy (SEM), energy dispersive spectroscopy (EDS), Fourier transform infrared spectroscopy using an attenuated reflectance device (FTIR-ATR) and thin-film X-ray diffraction (TF-XRD). Additionally, to evaluate the activity of the incorporated enzyme and the stability of the Ca-P films, coated samples were immersed in an SBF solution for different periods of time. The enzyme activity was measured and the morphology of the coating examined by SEM. The results obtained showed that the presence of protein molecules, at the nucleation or growth stages, lead to the formation of a dense Ca-P film presenting different morphologies that were different of the selected coating conditions. FTIR-ATR analysis detected the presence of carbonate and phosphate groups on the Ca-P layer, indicating the formation of a coating similar to the mineral component of vertebrates bone tissue. When proteins were added, amide I and amide II bands, characteristic groups of protein molecules, were also detected, revealing the efficient incorporation of these biomolecules into the Ca-P coatings.

Ca-P coatings, with $\alpha$-amylase incorporated at the nucleation stage, showed no degradation of the film after incubation in SBF for 28 days. The release of increasing concentration of reducing sugars with degradation time revealed that $\alpha$-amylase was efficiently incorporated in the coating remaining active throughout the coating preparation. This can be a strategy that will allow, in addition of conferring osteoconductive properties to biodegradable polymers, also simultaneously tailoring their degradation kinetics.
\end{abstract}

(C) 2005 Elsevier B.V. All rights reserved.

Keywords: Biodegradable polymers; Starch; Biomaterials; Biomimetic coatings; Calcium phosphate; Enzymes and proteins incorporation; Degradation; Bone

\section{Introduction}

Hydroxyapatite (HA) has been often designated as an osteoconductive material [1]. However, one common problem of ceramics, intended for load-bearing clinical applica-

\footnotetext{
* Corresponding author. 3B's Research Group, Biomaterials, Biodegradables and Biomimetics, University of Minho, Campus de Gualtar, 4710-057 Braga, Portugal. Tel.: +351 253604781; fax: +351253604492.

E-mail address: hazevedo@dep.uminho.pt (H.S. Azevedo).
}

tions, is their poor mechanical properties, such as low bending strength and brittle nature combined with low values of fracture toughness [2,3]. On the basis of these findings, adaptative interface functionalities were set as a target, keeping in mind that they should not compromise either chemical or physical bulk properties, and must simultaneously improve the tissue integration. This would open up the possibility of using non-bioactive materials including metals and non-metals that have the necessary strength and toughness to act as bone-bonding implant 
materials on load-bearing sites. HA can be effectively used as a coating material on a substrate that will ensure the biofunctionality.

In the last few years, coating orthopaedic implants with calcium phosphates (Ca-P) have been investigated, being proposed as a rather successful approach [4-7]. However, most of the available and common methods for producing adequate $\mathrm{Ca}-\mathrm{P}$ coatings, such as the plasma-spraying technique, are difficult to control on what concerns to the calcium phosphate (Ca-P) layer composition, degree of crystallinity and capability for strong adhesion to the substrates $[4,6,8,9]$. Generally, these techniques need temperatures of more than $500{ }^{\circ} \mathrm{C}$, which result in the degradation of $\mathrm{HA}$ to various calcium phosphate phases [10]. HA properties will tend to differ in chemical composition, in crystal structure as number of defects of apatite crystals, and/or in the crystallite sizes [11]. Furthermore, techniques that involve high temperatures are unsuitable for coating polymeric biomaterials and do not allow for the incorporation of bioactive agents into the coating.

To overcome the above-mentioned disadvantages, a biomimetic methodology, adapted from Kokubo et al. [11], has been used in our research group to produce Ca-P coatings on the surface of starch-based biomaterials [12-19] without requiring the use of high processing temperatures.

Bone growth into HA-coated implants is not always satisfactory. In fact, there is still a need for improvements regarding the induction of bone formation at the implantation site. There are indications [20] that the ion release from Ca-P coatings, as well as the composition and topography of the Ca-P layer, may indirectly affect cellular pathways like attachment and proliferation. These bioprocesses are involved in bone integration through altered ligand-cell receptor affinities, varied calcium and $\mathrm{pH}$-dependent enzyme kinetics, and a compositionally or structurally altered extracellular matrix protein environment [21,22]. For the successful application of these methodologies, there is the need to understand the integration process of newly formed bone as well as the calcification at HA-bone interface, so far could not be fully elucidated.

Mineralisation of bone is a highly organised process controlled by many kinds of modulators. These modulators may affect the nucleation and growth of the mineral phases. Several proteins have been identified to have the ability to induce bone formation, including the well-known bone morphogenetic proteins (BMPs) [23-27]. The functional groups of these biomolecules are thought to play a major role in inducing bone formation and binding to bone minerals, thus affecting a uniquely strong interface.

The use of nature inspired methods, such as biomimetic coatings, presents the advantage of using physiological conditions, like mild temperature and $\mathrm{pH}$. This in turn allows for incorporating bioactive species without compromising the performance of the coatings and to improve the functionality of the inorganic layer at the implantation interface. Several authors [28-41] have proposed models to explain the nucleation and formation of Ca-P layers in the presence of biomolecules. Proteins, enzymes, bone related proteins, mixtures and serum protein models, as other biologically important molecules, have been investigated for this purpose.

In this work, the possibility of incorporating proteins and enzymes at different stages of the preparation of Ca-P coatings by a biomimetic methodology was studied. Serum albumin was used as a model protein due to its concentration in the blood plasma, binding and diffusion properties. On the other hand, $\alpha$-amylase was exploited in terms of enzymatic properties, ability to interact with starch-based materials and tailor their degradation kinetics for a specific application. The influence of protein supplementation on the morphology, chemical composition, crystallinity and stability of the Ca-P coatings was investigated for both the nucleation and the growth stages. The adequacy of the selected procedure on the incorporation efficiency and activity of the biomolecules was also evaluated. In this case, the aim was to investigate the carrier potential of the $\mathrm{Ca}-\mathrm{P}$ coatings for sustained release applications.

\section{Experimental part}

\subsection{Materials}

The material used in this study was a biodegradable polymeric blend of corn starch with poly(ethylene-vinyl alcohol) copolymer (50/50 wt.\%), designated by SEVA-C. Using conventional injection moulding technology (Klockner-Ferromatik Desma FM20), $2 \times 4 \mathrm{~mm}^{2}$ cross-section dumb-bell ASTM tensile samples were produced. Further details on the material processing and respective mechanical properties can be found elsewhere $[42,43]$.

A bioactive glass (45S5 Bioglass ${ }^{\circledR}$ ) with the following composition: $45 \mathrm{SiO}_{2}, 24.5 \mathrm{CaO}, 24.5 \mathrm{Na}_{2} \mathrm{O}$ and $6.0 \mathrm{P}_{2} \mathrm{O}_{5}$ in wt.\%, was supplied by US Biomaterials Corp. (Florida, USA). This glass powder was used as precursor for calcium phosphate film deposition and, by laser scattering analysis (Coulter LS 100 particle size analyser), particle size was found to be lower than $20 \mu \mathrm{m}$.

Bovine serum albumin (BSA, Fraction V) was obtained from Sigma (St. Louis, USA) and $\alpha$-amylase, from Bacillus amyloliquefaciens, was gently supplied by Genencor International (Rochester, NY, USA).

\subsection{Preparation of $C a-P$ coatings-adapted biomimetic route}

The procedure used to produce Ca-P coating was based on the methodology previously developed by Abe et al. [11] and further adapted by Reis et al. [12,19]. Prior to the coating process, SEVA-C samples were sterilized by ethylene oxide in optimized conditions previously described [44]. 
Bioglass ${ }^{\circledR}(45 \mathrm{~S} 5)$ was sterilized by immersion in ethanol solution $(70 \%, \mathrm{v} / \mathrm{v})$ and allowed to dry inside the laminar flow cabinet. Protein and enzyme solutions were reconstituted to a final concentration of $1 \mathrm{mg} / \mathrm{ml}$ in simulated body fluid (SBF) solution ( $\mathrm{pH}$ 7.4) presenting ionic concentrations similar to human plasma. SBF and protein solutions were sterilized by filtration $(0.20 \mu \mathrm{m}$ pore). All the subsequent procedures were performed under sterile conditions in a vertical flow laminar cabinet to avoid samples and solutions contamination. The SEVA-C biomaterials were rolled on a bed of wet Bioglass ${ }^{\circledR}(45 \mathrm{~S} 5)$ particles and immediately immersed in $15 \mathrm{ml}$ of $1.0 \mathrm{SBF}$ solution. Incubation was allowed for 7 days at $37{ }^{\circ} \mathrm{C}$ for $\mathrm{Ca}-\mathrm{P}$ nuclei formation (nucleation stage). Following this period, samples were removed from the incubation solution, immersed in a 1.5 SBF solution and further incubated for 7 and 14 days in order to enable Ca-P nuclei growth (growth stage). SEVA-C samples were also incubated in SBF solution containing BSA or $\alpha$-amylase as described in Table 1.

After each immersion period, samples were taken from the incubation solution, rinsed with distilled water, dried at room temperature and stored before surface analysis. Incubation solutions were stored at $4{ }^{\circ} \mathrm{C}$ for element concentration and enzyme activity determinations.

\subsection{Characterisation of $\mathrm{Ca}-\mathrm{P}$ coatings}

\subsubsection{SEM and EDS}

Ca-P coatings morphology and presence of calcium, phosphorous and silicon elements on the coating surface were analysed before and after soaking in SBF, for the different experimental conditions and controls. This was carried out using scanning electron microscopy (SEM) coupled to energy dispersive spectroscopy (EDS) equipment (Leica Cambridge S360, UK). Previously to EDS and SEM analysis, sample surfaces were carbon coated (Fisons Instruments, Evaporation PSU CA508, UK) and gold sputtered (Fisons Instruments, Sputter Coater SC502, UK), respectively.

\subsubsection{FTIR-ATR}

The chemical structure of the coatings formed on the surface of SEVA-C under the different conditions studied was analysed by Fourier transform infrared spectroscopy with attenuated reflectance (FTIR-ATR). All condition spectra were recorded using at least 64 scans and $2 \mathrm{~cm}^{-1}$

Table 1

Solution compositions and respective immersion conditions for the incorporation of biomolecules into the biomimetic coatings

\begin{tabular}{lll}
\hline Condition & Nucleation stage & Growth stage \\
\hline A (Control) & $1.0 \mathrm{SBF}$ & $1.5 \mathrm{SBF}$ \\
$\mathrm{B}$ & $1.0 \mathrm{SBF}+\mathrm{BSA}(1 \mathrm{~g} / \mathrm{l})$ & $1.5 \mathrm{SBF}$ \\
$\mathrm{C}$ & $1.0 \mathrm{SBF}+\alpha$-amylase $(1 \mathrm{~g} / 1)$ & $1.5 \mathrm{SBF}$ \\
$\mathrm{D}$ & $1.0 \mathrm{SBF}$ & $1.5 \mathrm{SBF}+\mathrm{BSA}(1 \mathrm{~g} / 1)$ \\
$\mathrm{E}$ & $1.0 \mathrm{SBF}$ & $1.5 \mathrm{SBF}+\alpha$-amylase $(1 \mathrm{~g} / \mathrm{l})$ \\
\hline
\end{tabular}

resolution in an FTIR spectrophotometer (Perkin-Elmer 1600 Series, USA) and using a single reflection ATR system (MKII Golden Gate ${ }^{\mathrm{TM}}$, Specac, UK).

\subsection{3. $T F-X R D$}

Thin-film X-ray diffraction (TF-XRD, Philips X'Pert MPD, The Netherlands) was used to characterise the crystalline/amorphous nature of the films and to identify any crystalline phases present after immersion in SBF (results were compared to non-immersed controls). The data collection was performed by $2 \theta$ scan method with $1^{\circ}$ as incident beam angle using $\mathrm{CuK} \alpha \mathrm{X}$-ray line and a scan speed of $0.05^{\circ} / \mathrm{min}$ in $2 \theta$.

\subsubsection{Solution analysis}

Different sample solutions were analysed in order to determine the concentrations of calcium, phosphorus, silicon and sodium elements as a function of the immersion time. The element concentrations were measured by inductively coupled plasma optical emission spectroscopy (ICP-OES, JY 70 plus, Jobin Yvon, France). Duplicate samples were analysed for each condition and immersion time. Incubation solutions were also analysed to measure the activity of $\alpha$-amylase during the coating preparation. The dinitrosalicylic acid (DNS) method [45] was used to measure the concentration of reducing sugars produced as a result of starch hydrolysis. Adequate controls were prepared for assuring non-enzymatic material degradation effect.

\subsubsection{Stability of Ca-P coatings and evaluation of $\alpha$-amylase activity}

To evaluate the stability of the produced coatings, as well the activity of the incorporated enzyme, coated samples, prepared according with condition $\mathrm{C}$ (Table 1), were incubated in 1.0 SBF (pH 7.4) at $37{ }^{\circ} \mathrm{C}$ for 7,14 and 28 days. As described, after each degradation period the morphology of the coatings was analysed by SEM. Furthermore, enzyme activity, as function of incubation time, was determined by measuring the concentration of reducing sugars released into solution.

\section{Results}

\subsection{TF-XRD analysis}

In Fig. 1a, the TF-XRD patterns of SEVA-C surface after 14 days of immersion in the SBF (control) can be observed. By using non-immersed samples as controls surfaces, the characteristic main peaks of HA were evidenced and afterwards, confirmed by matching with the XRD spectra showing the standard HA pattern (JCPDS 9-432). Nevertheless, it seems that the apatite formed is mainly amorphous, as it was detected in other types of biomimetic coatings $[15,19]$. 

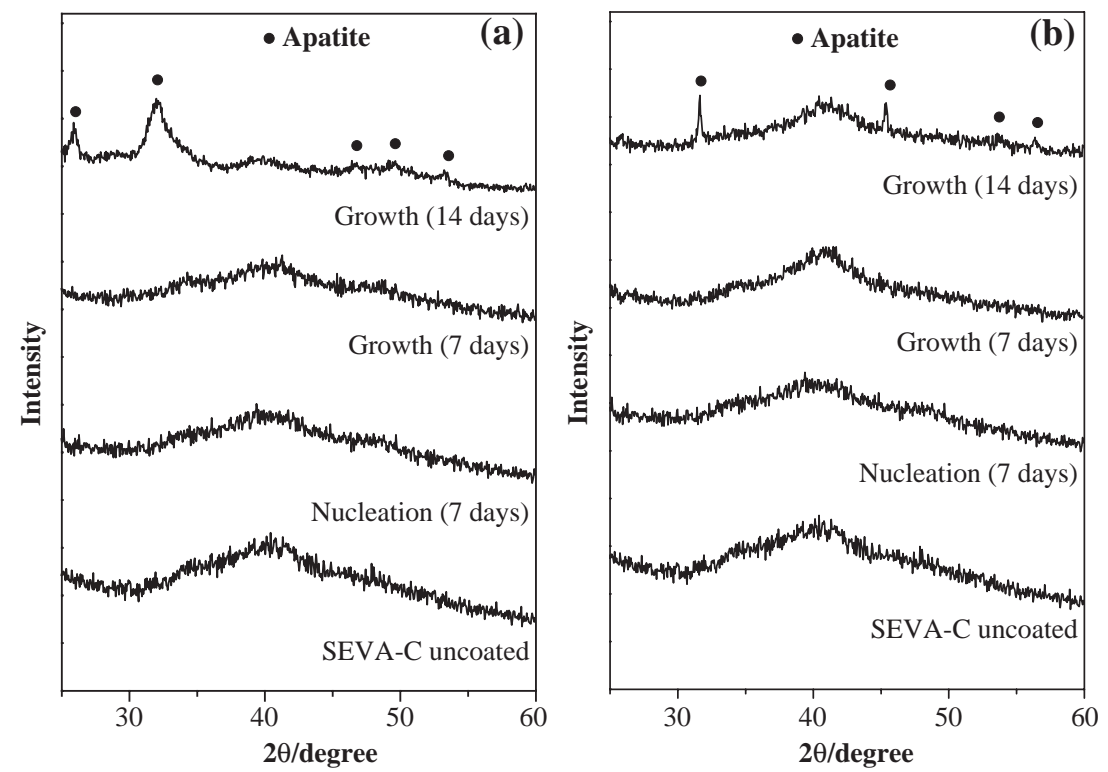

Fig. 1. TF-XRD patterns of the Ca-P coatings produced on SEVA-C surface after the nucleation stage (7 days), and growth stage (7 and 14 days) for conditions A (a) and $E(b)$.

In condition $\mathrm{E}$ (where $\alpha$-amylase was added during the growth stage), after 14 days in SBF, two diffraction peaks that can be assigned to an apatite-like phase (ASTM JCPDS 9-432) (Fig. 1b) was observed. However, again, the film was rather amorphous.

The lower intensity of the diffraction of the apatite phase indicates that in the nucleation stage a much thinner apatite layer was formed on the specimen surface. Also, this fact was observed for the other conditions. Studies have been relating the presence of proteins with a lower crystallinity of minerals, such as apatite in bone [46].

\subsection{FTIR-ATR analysis}

In the control (condition A) after soaking in SBF for 7 days in the growth stage, the FTIR-ATR spectrum displays reflectance bands associated with apatitic phosphate group (the group band at $1018 \mathrm{~cm}^{-1}$ ), and bands associated with carbonate substitution (the group band at $1418 \mathrm{~cm}^{-1}$ ). As the soaking time increases these bands were observed to be more intense (Fig. 2a).

When $\alpha$-amylase and BSA were added to the SBF solution, either in nucleation or growth stages, chemical changes were observed in the IR spectra at $1650 \mathrm{~cm}^{-1}$. This can be ascribed to the amide I band that represents the stretching vibrations of $\mathrm{C}=\mathrm{O}$ bonds in the backbone of the protein (Fig. 2b and c) [47]. In turn, obtained results could indicate adsorption of proteins on the surface of the substrate. Furthermore, in conditions D and E, after 7 days and during the growth stage in SBF solution, FT-IR spectra shows bands centered at 1650 and $1542 \mathrm{~cm}^{-1}$ that can be attributed to amide I and amide II, respectively (Fig. 2c) [47]. The amide II band arises from the combination of C-N stretching and $\mathrm{N}-\mathrm{H}$ bending vibrations of the protein backbone [47], which observation confirms again the incorporation of biomolecules into the coating.

Moreover, carbonate and phosphate bands, located, respectively at 1418 and $1020 \mathrm{~cm}^{-1}$, were observed in the collected spectra. These results confirm that the apatite layer formed on the surface of this polymer is a carbonated apatite mineral similar to the major mineral component of bone [48].

\subsection{SEM and EDS analysis}

Fig. 3 shows the SEM micrographs of the calcium phosphate coatings onto SEVA-C surface before and after soaking in SBF solution for different conditions. The observed calcium phosphate coatings were observed as uniform layers covering SEVA-C substrate for all the studied conditions.

However, some significant differences were found between all conditions. When BSA and $\alpha$-amylase were added to the SBF solution in the nucleation stage (conditions $\mathrm{B}$ and $\mathrm{C}$ ), only the formation of apatite nuclei was observed, meaning that increasing soaking time in SBF did not promote growth of the Ca-P layer (please see Fig. 3c and d). Quite the opposite was observed when the same biomolecules were added in the SBF solution during the growth stage (conditions D and E-Fig. 3e and f). For conditions $\mathrm{D}$ and $\mathrm{E}$, in the first 7 days in the growth stage, only the formation of apatite nuclei was possible to observe on the SEVA-C surface. Furthermore, for condition E, as the soaking time increased, the Ca-P film becomes denser and compact.

The incorporation of BSA was found to change the morphology of the coating both in the nucleation and growth stage: the size of Ca-P nuclei did not increase and 

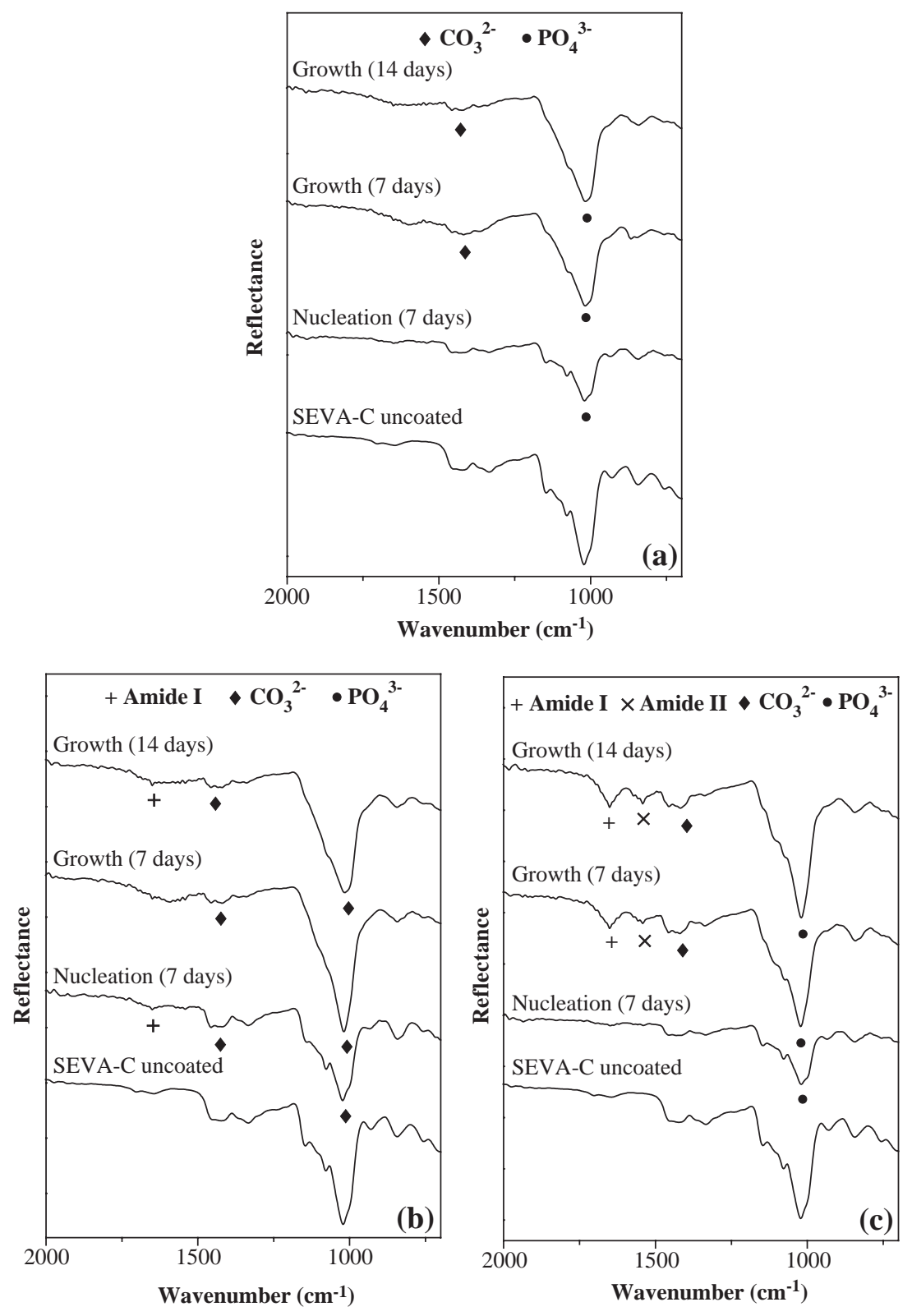

Fig. 2. FTIR-ATR spectra of the Ca-P coatings produced on SEVA-C surface before coating and after nucleation and growth stages for conditions A (a), B (b) and $\mathrm{D}(\mathrm{c})$

consequently the film did not grow as function of immersion time. Regarding the presence of $\alpha$-amylase in the growth stage, the effect was the opposite. With increasing soaking time, Ca-P nuclei grew in size by consuming the calcium and phosphorus ions from the SBF solution, resulting in turn in the formation of a denser CaP film (Fig. 3f). This behaviour was also found by other authors [49].

EDS analysis (data not shown) confirmed the presence of silicon $(\mathrm{Si})$ element as well as the calcium $(\mathrm{Ca})$ and phosphorus $(\mathrm{P})$ signal elements after 7 days in the nucleation stage. In the growth stage, only $\mathrm{P}$ and $\mathrm{Ca}$ signals were detected. Herein, signal intensity significantly increased indicating in turn density increase of the Ca-P coating.

\subsection{ICP analysis}

The variation of $\mathrm{Ca}, \mathrm{P}, \mathrm{Si}$ and $\mathrm{Na}$ concentrations in conditions $\mathrm{D}$ and $\mathrm{E}$ are shown in Fig. 4 as a function of immersion time in SBF solution for nucleation and growth stages.

In the nucleation stage of both conditions, an accentuated increase of $\mathrm{Si}$ and $\mathrm{Na}$ concentrations was observed, being attributed to the dissolution of the bioactive glass particles. Also, the decrease in the $\mathrm{Ca}$ and $\mathrm{P}$ concentration in the solution in the first immersion days confirms the nucleation of Ca-P layer on the immersed sample.

Moreover, the water uptake capability of SEVA-C allowed the material to absorb higher quantities of $\mathrm{Ca}^{2+}$ 

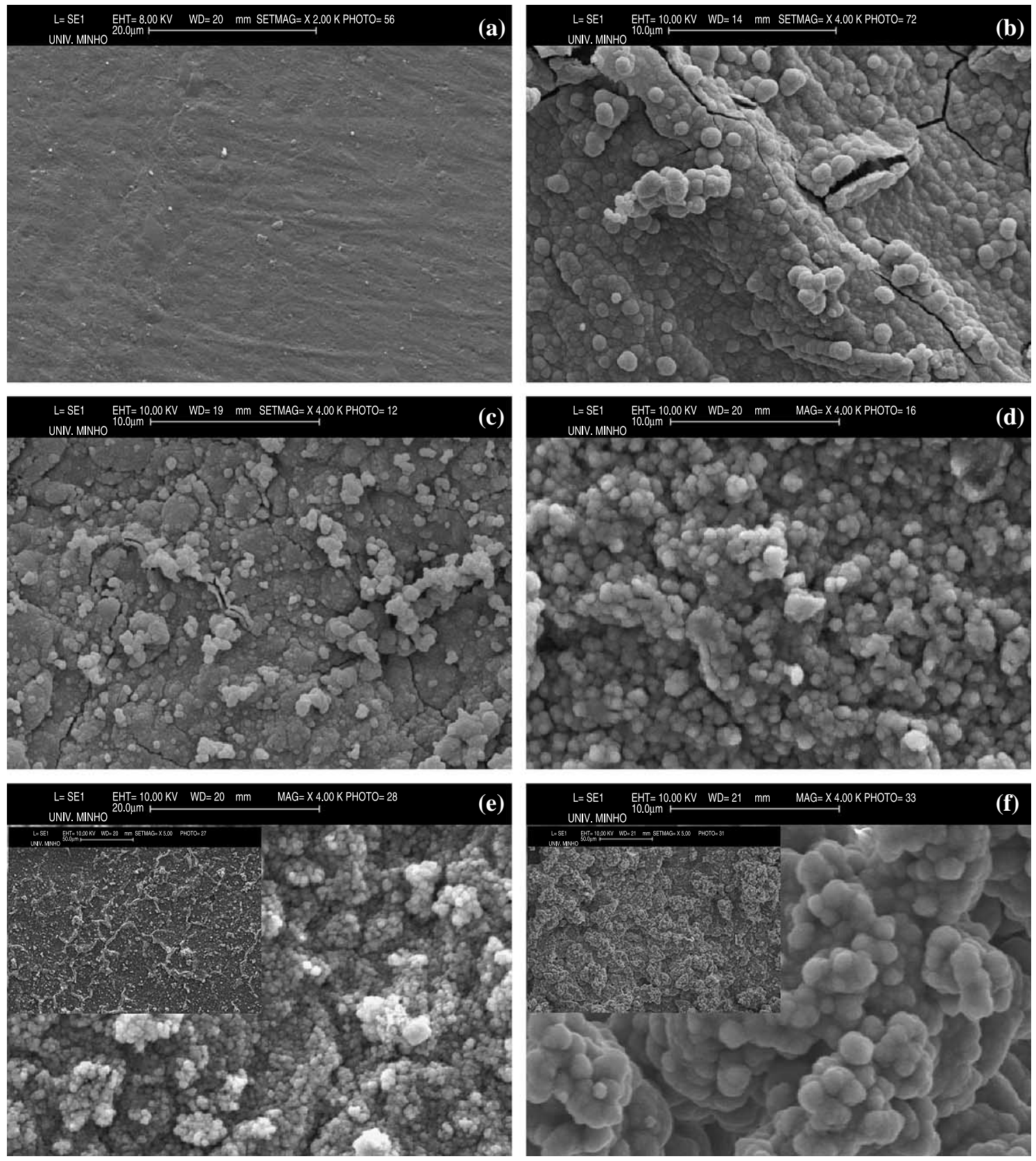

Fig. 3. SEM micrographs of the Ca-P coatings produced on the surfaces of SEVA-C before coating (a), and after 14 days in SBF (growth stage). (b) Control, (c) BSA and (d) $\alpha$-amylase added in the nucleation stage, (e) BSA and (f) $\alpha$-amylase added in the growth stage.

and $\mathrm{PO}_{4}^{3-}$ ions from the solution. In the growth stage, for both conditions, there was a large number of Ca-P nuclei formed that induce a spontaneous growth of the Ca-P filmconsuming $\mathrm{Ca}^{2+}$ and $\mathrm{PO}_{4}^{3-}$ ions from $\mathrm{SBF}$ solution. As the immersion time increases, $\mathrm{Ca}$ and $\mathrm{P}$ concentrations decreased gradually probably due to the Ca-P formation by consuming the calcium and phosphate ions in SBF. However, in condition D, in the first 7 days in the growth stage, there was a steep decrease in the calcium and phosphorus concentrations, as it is shown in Fig. 4a. As a result, the calcium phosphate nuclei formed in this condition did not grow due to a quick consumption of such species from SBF (Fig. 3e).

\subsection{Stability of $C a-P$ coatings and evaluation of $\alpha$-amylase activity}

In vitro dissolution of Ca-P materials depends on their composition, surface area, surface topography, micro- and macroporosities, and crystallinity [50]. Independently from the degree of crystallinity, all Ca-P coatings will dissolve or degrade to some extent. The amorphous phases are expected to dissolve first than crystalline compounds. There is, therefore, the possibility to produce a $\mathrm{Ca}-\mathrm{P}$ coating with the biodegradation rate desired for particular applications, by varying the crystallinity, composition and microstructure of the coating. 
In this study, the stability of Ca-P coating, prepared according to condition $\mathrm{C}$ (incorporation of $\alpha$-amylase at nucleation stage) was examined by SEM. The coating morphology after immersion in 1.0 SBF (Fig. 5) shows that the typical morphology of Ca-P coatings remained unchanged even after 28 days of immersion. Liu et al. $[49,51]$ reported that the dissolution of Ca-P coatings on the surface of titanium implants was reduced when BSA was incorporated in the coating. It was postulated that the protein was able to reduce the release of $\mathrm{Ca}$ from the coating and to enhance the adhesion between the coating and titanium. Further studies should investigate the effect of protein incorporation at the nucleation and growth stages on the dissolution rate of the Ca-P coating by measuring the release of calcium and phosphorus elements, as well as the protein. Also, monitoring changes on the crystallinity, composition and thickness of the film would be interesting.

$\alpha$-Amylase is an endo-specific enzyme which catalyses the hydrolysis of $\alpha-1,4$-glycosidic linkages of starch to maltose and dextrins, reducing the molecular size of starch. The activity of $\alpha$-amylase may be detected by measuring the soluble reducing ends released into the solution as a result of starch hydrolysis. To assess if $\alpha$-amylase remained active after being incorporated in Ca-P coating, coated samples
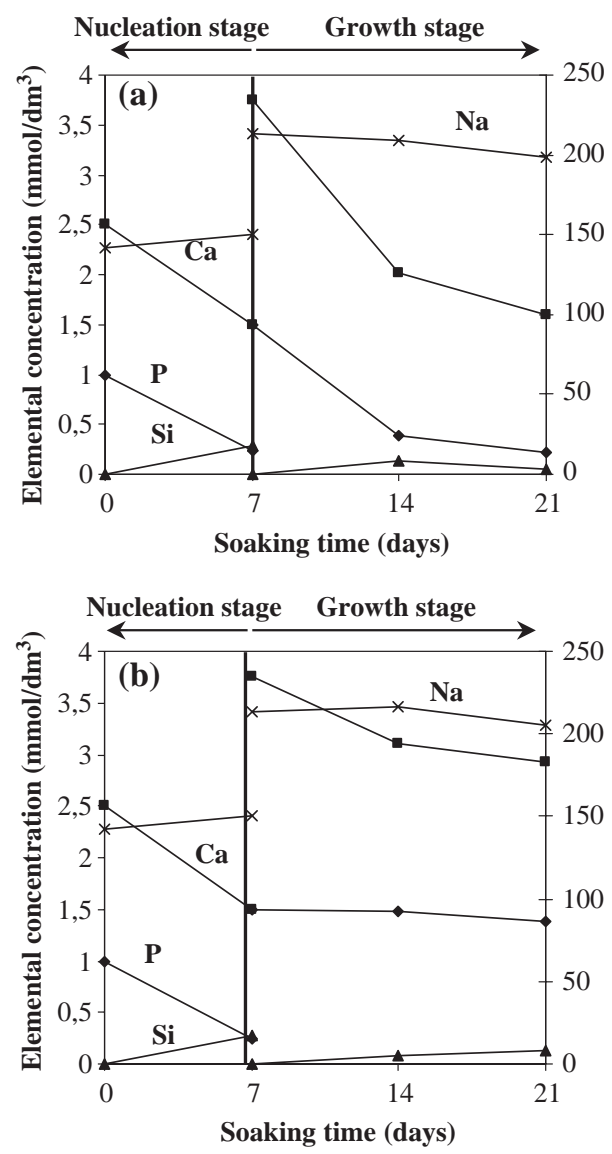

Fig. 4. Evolution of $\mathrm{Ca}, \mathrm{P}, \mathrm{Si}$ and $\mathrm{Na}$ concentrations in $\mathrm{SBF}$ as function of immersion time in the nucleation and growth stages for conditions D (a) and E (b). (prepared according with condition C) were immersed in 1.0 SBF and incubated at $37{ }^{\circ} \mathrm{C}$ for different periods of time. Analysing the results presented in Fig. 6, it is possible to observe that the concentration of reducing sugars increased with incubation time, indicating that the methodology used to produce $\mathrm{Ca}-\mathrm{P}$ coatings did not have a denaturation effect on the enzyme activity and that the enzyme remained active to further catalyse the hydrolysis of starch. This demonstrates that $\alpha$-amylase was efficiently incorporated in the coating and only Ca-P dissolution might trigger the release of the enzyme.

\section{Discussion}

With the biomimetic coating methodology it was possible to incorporate biomolecules, such as BSA and $\alpha$ amylase. However, there were some considerable differences between the incorporation of biomolecules in the nucleation and growth stage.

The effect of proteins on the formation of Ca-P coatings has been subjected to an extensive research $[28,29,38,51-$ 55]. Most of these studies aimed to investigate the possible role of plasma proteins on the formation of an apatite layer in vivo, but few had exploited the possibility of incorporating therapeutic agents into Ca-P films to develop a delivery system for the sustained release of biomolecules.

Proteins are highly surface-active molecules due to their amphiphilic properties [56]. Hence, they can interact with any encounter interface, generally leading to adsorption of the proteins $[57,58]$ that is responsible for a range of initial and fate-determining interactions [59]. Albumin, specifically, was selected for this study due to its high concentration in the blood serum, favourable diffusion coefficient and ability to bind other molecules [60,61]. On the other hand, $\alpha$-amylase was used as appropriate to study enzymatic properties and due to its ability to interact with starch-based materials [62].

It was found that the adsorption of proteins on the mineral surface can alter the nucleation and growth process, acting as promoters or inhibitors of biomineralisation, depending on the concentration of adsorbed proteins [29]. Combes et al. [29] observed that BSA had two opposite effects on the growth kinetics of octacalcium phosphate (OCP) on type I collagen. At concentrations lower than 10 $\mathrm{mg} / \mathrm{ml}$, BSA favoured the growth of OCP, whereas at higher concentrations (up to $60 \mathrm{mg} / \mathrm{ml}$ ) BSA presented an inhibitory effect. In the presence of about $1 \mathrm{mg} / \mathrm{ml}$ of $\mathrm{BSA}$, the OCP growth rate was twice higher than in the absence of BSA. In this study, the concentration of BSA and $\alpha$-amylase used was $1 \mathrm{mg} / \mathrm{ml}$ and this may explain the fact that no inhibitory effect was observed when the proteins were added to the SBF solutions.

It is well known that anionic substances, especially those containing phosphate or phosphonate groups, are quite efficient in regulating calcium phosphate crystallisation 

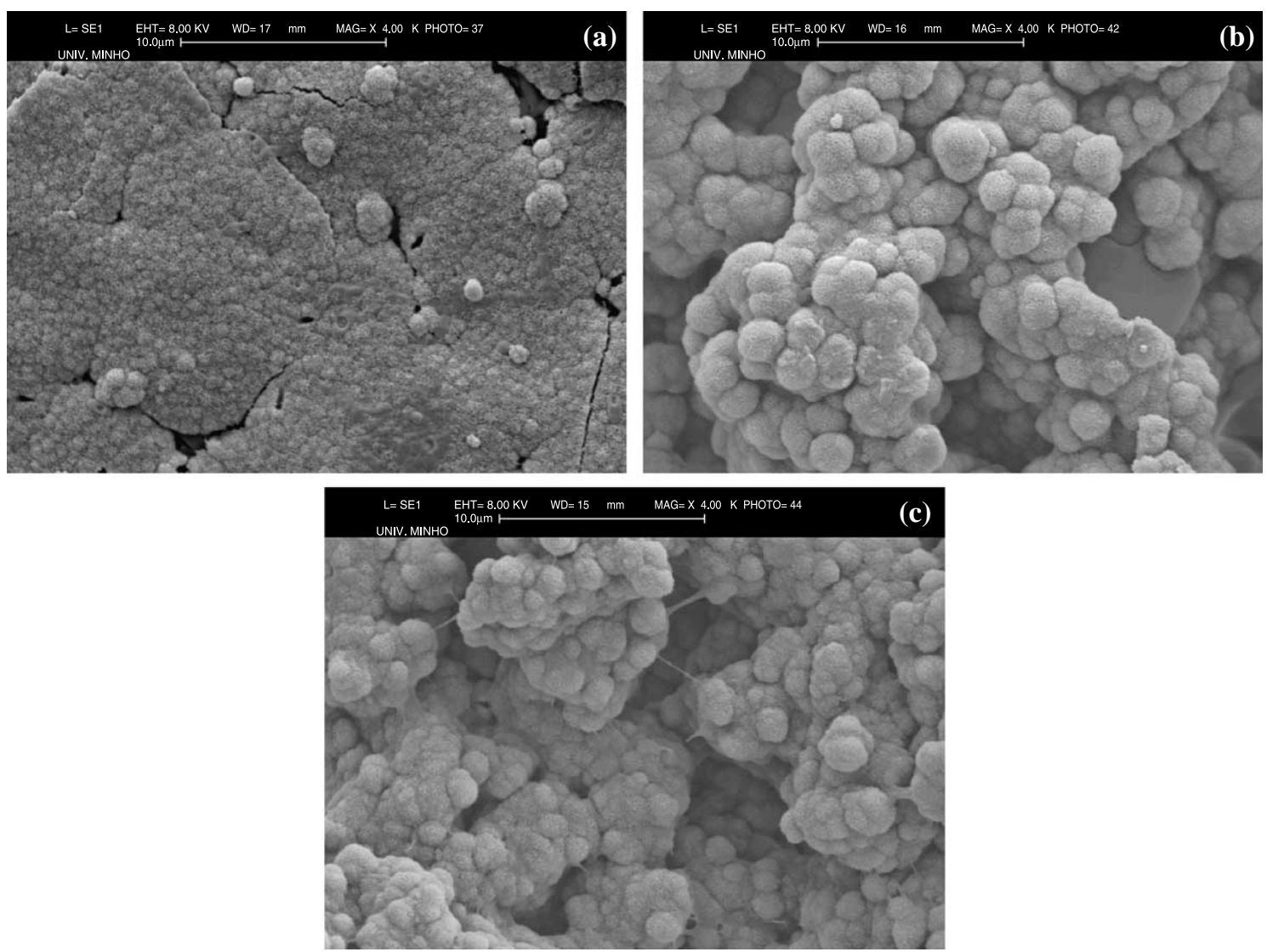

Fig. 5. SEM micrographs of the Ca-P coatings, produced according with the conditions described for condition C, after incubation in $1.0 \mathrm{SBF}$ at $37^{\circ} \mathrm{C}$ for 7 (a), 14 (b) and 28 (c) days.

through adsorption at specific crystal growth sites. The isoelectric points of BSA and $\alpha$-amylase are 4.7 and 5.7, respectively, which means, that at the physiological $\mathrm{pH}$ (7.4), these proteins are negatively charged and tend spontaneous to bind positive ions like $\mathrm{Ca}^{2+}$ ones present in the environment solution [58]. Furthermore, serum albumin and most $\alpha$-amylases contain calcium-binding sites $[63,64]$. The presence of these cations may affect the

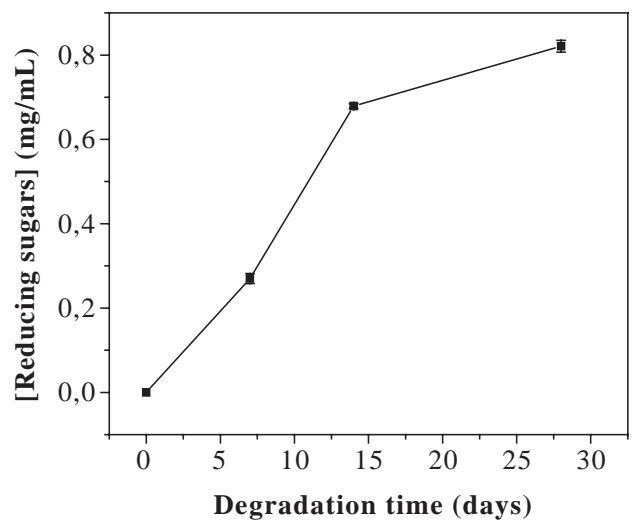

Fig. 6. Concentration of reducing sugars produced during the incubation of coated SEVA-C samples (with $\alpha$-amylase incorporated in the nucleation stage - condition C) in 1.0 SBF (pH 7.4) at $37{ }^{\circ} \mathrm{C}$ for different periods of time. conformational stability of these proteins and consequently their adsorption and activity profile. These phenomena would, therefore, strongly affect $\mathrm{Ca}^{2+}$ ions availability for the formation and growth of Ca-P nuclei [51].

It has been suggested that there are two general types of Ca-P coatings inhibitors: those affecting nucleation and those affecting growth, since both these mechanisms are quite different. A protein may act in different ways against crystal nucleation and growth. The effect of protein adsorption in the nucleation stage is complex since protein adsorption may occur on the substrate and on the Ca-P nuclei. Combes and Rey [28] proposed a model, based on experimental data and thermodynamic considerations, which describe the influence of protein adsorption on the nucleation and growth processes during formation of Ca-P coatings. The addition of proteins at different stages of the preparation of Ca-P coatings is expected, therefore, to produce coatings with distinct characteristics.

The results obtained in the present work show differences on the properties of the developed coatings namely on their composition and morphology. FTIR analyses confirmed the formation of a calcium phosphate layer on the surface of the polymeric material in all the conditions studied, as detected by the presence of phosphate and carbonate groups. In particular, when BSA was incorporated either in the nucleation or growth stage, the 
formation of a crystalline and a dense Ca-P layer was delayed. This effect was more pronounced in condition $\mathrm{D}$, as it was observed by SEM. This can be interpreted in terms of interactions between the protein with the bioactive glass particles (nucleating agent) and with the starch polymeric material (substrate). It is possible that in condition B such interactions might have occurred, where there is a competition between the substrate and the nucleating agent. In this situation, BSA might have adsorbed on the surface of SEVA-C and also on Bioglass. The presence of the protein layer on the glass surface could reduce or prevent the ionic exchange that must be established at interface with the substrate. Ducheyne et al. [39,65] and Wen et al. [66] had observed the same behaviour. As result, in condition $\mathrm{B}$, the formation of $\mathrm{Ca}-\mathrm{P}$ film was delayed, once it was only observed in the growth stage and after 14 days (please see Fig. 3c). Moreover, in the FTIR spectra, the intensity of the characteristics bands of proteins was not so intense, which may indicate no adsorption of BSA on the SEVA-C and can suggest its adsorption onto the glass surface.

The ICP analysis provided additional information on the effect of the incorporation of the two biomolecules on the formation of the biomimetic coating. The dissolution, ion exchange, and precipitation reactions were observed even in the presence of BSA and $\alpha$-amylase, changing only the reaction rate. So, when BSA is adsorbed on the surface of SEVA-C, the concentration of $\mathrm{Ca}$ in the SBF solution decreases significantly. It is suggested that BSA is capturing the $\mathrm{Ca}$ ions from the SBF solution (confirmed by ICP analysis). These ions may also act as bridges between the negatively charged proteins and the hydroxyl groups pre-exposed on the SEVA-C surface. In condition $\mathrm{D}$, the accentuated decrease of $\mathrm{Ca}$ from the solution may be due to the competitive binding of calcium ions to the molecule of albumin and therefore the film did not grow after 14 days, only the formation of Ca-P nuclei film had occurred. This may be related with the adsorption of BSA on the Ca-P nucleus film and, as result, they cannot be active for crystal growth. Since there is an accentuated decrease of calcium from the solution (see Fig. 4a), the nucleus can grow in number but not in size. Such results had been found by Combes et al. [29] who explained that the adsorption of albumin decreases the interfacial energy of the Ca-P nuclei and therefore stabilizes nuclei with smaller radii. The formation of such small nuclei is facilitated and their number can thus increase rapidly.

The different coating morphologies observed for BSA and $\alpha$-amylase incorporation may be related with their amino acid composition, conformational structure and adsorption behaviour. This will influence the type and number of amino acids, as well as their orientation, which will be exposed at the surface. These functional groups may be involved in the initial stages of mineral formation through complexation of calcium cations, which in turn attract phosphate anions.
It was also reported that, when present in solution, some proteins were capable of inhibiting the formation of calcium phosphates, either by binding calcium or phosphate or by adsorbing onto apatite surfaces, thus blocking active growth sites. The immobilisation of those proteins (adsorbed as a film or bound to a support material) showed, on the contrary, to initiate mineral formation $[30,67]$. It is believed that, when the protein is adsorbed, it will complex with calcium at the surface, inducing precipitation, whereas the complexation in solution retards the precipitation. Campbell and Nancollas [31] investigated the ability of various salivary proteins to mineralise hydroxyapatite, when immobilised as films, and found that salivary amylase was shown to be the most active protein in inducing the nucleation and growth of calcium phosphate. This may confirm the results found with $\alpha$-amylase, although in the present study the proteins were used in solution. It should be considered, however, that there are strong evidences that $\alpha$-amylase had adsorbed on the material surface, since it was detected the production of reducing sugars during the various stages of incubation (data not shown). The hydrolysis of starch is only possible by the pre-adsorption of the enzyme to the substrate. It is well known that the adsorption of polysaccharide-degrading enzymes to insoluble substrates is a prerequisite step before catalysis and these enzymes exhibit high affinity and bind specifically to their substrates [68].

Different behaviours have been reported in the literature concerning the effect of proteins on the nucleation and inhibition of hydroxyapatite formation. This is mainly due to the diversity of experimental systems used, which makes it difficult to find an overall conclusion. Having into account the various interactions that can be established between the proteins, the substrate and the various ions present in solution during the nucleation and growth stages, the mineralisation process in the presence of biological molecules can be considered a rather complex subject. Consequently, more sophisticated analysis techniques are needed to better understand the multiple events occurring in the process. Even though, these results suggest that it is possible to tailor the properties of the coatings. Porosity, mechanical properties, dissolution rate, release profile and cellular response are also expected to be affected by the selection of proper proteins and its incorporation at different stages of the coating preparation.

\section{Conclusion}

In this work, BSA and $\alpha$-amylase were successfully incorporated into a Ca-P coating on the surface of starchbased polymer using a biomimetic technique. The addition of proteins with distinct characteristics to the SBF solutions, at different stages of the Ca-P coating formation, affected the composition, structure and morphology of the 
obtained Ca-P layer. This enables the possibility of tailoring the properties of biomaterials by incorporating specific proteins at different compositions and combinations into Ca-P coatings. Furthermore, this methodology proved to be able to preserve the activities of enzymes. Herein indicating the carrier potential of calcium phosphate coatings for the sustained delivery of other bioactive agents. The efficient incorporation of active $\alpha$-amylase into Ca-P coatings may be used, for instance, as a method to control the degradation rate of starch-based biomaterials. These results enable definitively for the new perspective of adding osteoinductive proteins or growth factors into biomimetic coatings, for inducing bone growth on the implant surroundings.

Further studies should be carried out to investigate in more detail the dissolution of Ca-P coatings, with or without proteins incorporated at the nucleation or growth stages, and the release profile of the entrapped proteins. Cell studies should also investigate the effect of the resultant Ca-P coating in the morphology, adhesiveness, proliferation and differentiation of bone-like cells.

\section{Acknowledgement}

This work was partially supported by Portuguese Foundation for Science and Technology (FCT) and was performed within the framework of the project BIOLEARN (POCTI/CTM/38803/2001) through funds from the POCTI and/or FEDER Programmes. H. S. Azevedo would also like to thank FCT for providing her a postdoctoral scholarship (Grant SFRH/BPD/5744/2001).

\section{References}

[1] L.L. Hench, Biomaterials 19 (1998) 1419.

[2] W.P. Cao, L.L. Hench, Ceramics International 22 (1996) 493.

[3] F. Mestral, R.A.L. Drew, Journal of the European Ceramic Society 5 (1989) 47.

[4] K.A. Gross, C.C. Berndt, Journal of Biomedical Materials Research 39 (1998) 580.

[5] L. Clèries, J.M. Fernandez-Pradas, J.L. Morenza, Biomaterials 21 (2000) 1861.

[6] M. Wei, A.J. Ruys, M.V. Swain, S.H. Kim, B.K. Milthorpe, C.C. Sorrell, Journal of Materials Science. Materials in Medicine 10 (1999) 401.

[7] K. Yamashita, T. Arashi, K. Kitagaki, S. Yamada, T. Umegaki, K. Ogawa, Journal of the American Ceramic Society 77 (1994) 2401.

[8] K. Hayashi, T. Inadome, T. Mashima, Y. Sugioka, Journal of Biomedical Materials Research 27 (1993) 557.

[9] M. Tanahashi, T. Yao, T. Kokubo, M. Minoda, T. Miyamoto, T. Nakamura, T. Yamamuro, Journal of Biomedical Materials Research 29 (1995) 349.

[10] F. Fazan, P.M. Marquis, Journal of Materials Science. Materials in Medicine 11 (2000) 787.

[11] Y. Abe, T. Kokubo, T. Yamamuro, Journal of Materials Science. Materials in Medicine 1 (1990) 233.

[12] A.L. Oliveira, C. Elvira, R.L. Reis, B. Vazquez, J. San Roman, Journal of Materials Science. Materials in Medicine 10 (1999) 827.
[13] A.L. Oliveira, C.M. Alves, R.L. Reis, Journal of Materials Science. Materials in Medicine 13 (2002) 1181.

[14] A.L. Oliveira, I.B. Leonor, C. Elvira, M.C. Azevedo, I. Pashkuleva, R.L. Reis, in: R.L. Reis, D. Cohn (Eds.), Polymer Based Systems on Tissue Engineering, Replacement and Regeneration, Kluwer Press, Drodercht, 2002, p. 183.

[15] A.L. Oliveira, M.E. Gomes, P.B. Malafaya, R.L. Reis, in: B. BenNissan, D. Sher, W. Walsh (Eds.), Bioceramics, 15, Trans Tech Publications, Zurich, 2003, p. 101.

[16] A.L. Oliveira, I.B. Leonor, P.B. Malafaya, C.M. Alves, H.S. Azevedo, R.L. Reis, in: B. Ben-Nissan, D. Sher, W. Walsh (Eds.), Bioceramics, 15, Trans Tech Publications, Zurich, 2003, p. 111.

[17] A.L. Oliveira, J.F. Mano, R.L. Reis, Current Opinion in Solid State and Materials Science 7 (2003) 309

[18] A.L. Oliveira, P.B. Malafaya, R.L. Reis, Biomaterials 24 (2003) 2575.

[19] R.L. Reis, A.M. Cunha, M.H. Fernandes, R.N. Correia, Journal of Materials Science, Materials in Medicine 8 (1997) 897.

[20] P. Ducheyne, Q. Qiu, Biomaterials 20 (1999) 2287.

[21] D.E. MacDonald, F. Betts, M. Stranick, S. Doty, A.L. Boskey, Journal of Biomedical Materials Research 54 (2001) 480.

[22] E.M. Burke, J.D. Haman, J.J. Weimer, A.B. Cheney, J.M. Rigsbee, L.C. Lucas, Journal of Biomedical Materials Research 57 (2001) 41.

[23] T. Kaito, A. Myoui, K. Takaoka, N. Saito, M. Nishikawa, N. Tamai, H. Ohgushi, H. Yoshikawa, Biomaterials 26 (2005) 73.

[24] C.A. Kirker-Head, Advanced Drug Delivery Reviews 43 (2000) 65.

[25] J.R. Lieberman, A. Daluiski, T.A. Einhorn, Journal of Bone and Joint Surgery. American Volume 84-A (2002) 1032.

[26] Y. Tabata, Tissue Engineering 9 (2003) S5.

[27] L.C. Yeh, M.C. Zavala, J.C. Lee, Journal of Cellular Physiology 190 (2002) 322.

[28] C. Combes, C. Rey, Biomaterials 23 (2002) 2817.

[29] C. Combes, C. Rey, M. Freche, Journal of Materials Science. Materials in Medicine 10 (1999) 153.

[30] D. Couchourel, C. Escoffier, R. Rohanizadeh, S. Bohic, G. Daculsi, Y. Fortun, M. Padrines, Journal of Inorganic Biochemistry 73 (1999) 129.

[31] A.A. Campbell, G.H. Nancollas, Colloids and Surfaces 54 (1991) 33.

[32] S.A. Bender, J.D. Bumgardner, M.D. Roach, K. Bessho, J.L. Ong, Biomaterials 21 (2000) 299.

[33] R. Fujisawa, Y. Kuboki, Biochimica et Biophysica Acta 1075 (1991) 56.

[34] G.K. Hunter, P.V. Hauschka, A.R. Poole, L.C. Rosenberg, H.A. Goldberg, Biochemical Journal 317 (Pt. 1) (1996) 59.

[35] K.D. Lobel, L.L. Hench, Journal of Biomedical Materials Research 39 (1998) 575.

[36] A. Krajewski, R. Malavolti, A. Piancastelli, Biomaterials 17 (1996) 53.

[37] R.I. Martin, P.W. Brown, Journal of Materials Science. Materials in Medicine 5 (1994) 96.

[38] J. Mei, R.M. Shelton, P.M. Marquis, Journal of Materials Science. Materials in Medicine 6 (1995) 703.

[39] H.H. Lu, S.R. Pollack, P. Ducheyne, Journal of Biomedical Materials Research 54 (2001) 454.

[40] F.H. Shen, Q.L. Feng, C.M. Wang, Journal of Crystal Growth 242 (2002) 239.

[41] J. Xie, C. Riley, K. Chittur, Journal of Biomedical Materials Research 57 (2001) 357.

[42] R.L. Reis, A.M. Cunha, P.S. Allan, M.J. Bevis, Polymers for Advanced Technologies 7 (1996) 784.

[43] R.L. Reis, A.M. Cunha, in: K.H.J. Buschow, R.W. Cahn, M.C. Flemings, B. Ilschner, E.J. Kramer, S. Mahajan (Eds.), Biological and Biomimetic Materials, Pergamon-Elsevier Science, Amsterdam, 2001, p. 8810 .

[44] R.L. Reis, S.C. Mendes, A.M. Cunha, M.J. Bevis, Polymer International 43 (1997) 347.

[45] T.K. Ghose, Pure and Applied Chemistry 59 (1987) 257. 
[46] H.B. Wen, J.R. de Wijn, C.A. van Blitterswijk, K. de Groot, Journal of Biomedical Materials Research 46 (1999) 245.

[47] J. Xie, C. Riley, M. Kumar, K. Chittur, Biomaterials 23 (2002) 3609.

[48] S. Mann, Biomineralization, Principles and Concepts in Bioinorganic Materials Chemistry, Oxford University Press, Oxford, 2001.

[49] Y. Liu, M. Stigter, K.d. Groot, P. Layrolle, in: S. Brown, I. Clarke, P. Williams (Eds.), Bioceramics 14. Trans Tech Publications, Zurich, 2002, p. 157.

[50] R.Z. LeGeros, Clinical Orthopaedics (2002) 81.

[51] Y. Liu, P. Layrolle, J. de Bruijn, C. van Blitterswijk, K. de Groot, Journal of Biomedical Materials Research 57 (2001) 327.

[52] S. Radin, P. Ducheyne, Journal of Biomedical Materials Research 30 (1996) 273-279.

[53] S. Radin, P. Ducheyne, B. Rothman, A. Conti, Journal of Biomedical Materials Research 37 (1997) 363.

[54] A. Serro, B. Saramago, Journal of Biomedical Materials Research 49 (2000) 345.

[55] B. Feng, J. Chen, X. Zhang, Biomaterials 23 (2002) 2499.

[56] W. Norde, Advances in Colloid Interface Science 25 (1986) 267.

[57] K. Nakanishi, T. Sakiyama, K. Imamura, Journal of Bioscience and Bioengineering 91 (2001) 233.

[58] T. Suzawa, H. Shirahama, Advances in Colloid and Interface Science 35 (1991) 139.

[59] C. Mannhalter, Sensors and Actuators. B, Chemical 11 (1993) 273.
[60] C. Oehr, Nuclear Instruments and Methods in Physics Research. Section B, Beam Interactions with Materials and Atoms 208 (2003) 40.

[61] C.R. Jenney, J.M. Anderson, Journal of Biomedical Materials Research 49 (2000) 435

[62] H.S. Azevedo, F.M. Gama, R.L. Reis, Biomacromolecules 4 (2003) 1703.

[63] A. Klinger, D. Steinberg, D. Kohavi, M.N. Sela, Journal of Biomedical Materials Research 36 (1997) 387.

[64] E. Boel, L. Brady, A.M. Brzozowski, Z. Derewenda, G.G. Dodson, V.J. Jensen, S.B. Petersen, H. Swift, L. Thim, H.F. Woldike, Biochemistry 29 (1990) 6244.

[65] E.A. Kaufmann, P. Ducheyne, S. Radin, D.A. Bonnell, R. Composto, Journal of Biomedical Materials Research 52 (2000) 825.

[66] H.B. Wen, J. Moradian-Oldak, J.P. Zhong, D.C. Greenspan, A.G. Fincham, Journal of Biomedical Materials Research 52 (2000) 762.

[67] P.A. Marques, A.P. Serro, B.J. Saramago, A.C. Fernandes, M.C. Magalhaes, R.N. Correia, Biomaterials 24 (2003) 451.

[68] A.B. Boraston, B.W. McLean, J.M. Kormos, M. Alam, N.R. Gilkes, C.A. Haynes, P. Tomme, D.G. Kilburn, R.A.J. Warren, in: H.J. Gilbert, G.J. Davies, B. Henrissat, B. Svenson (Eds.), Recent Advances in Carbohydrate Bioengineering, The Royal Society of Chemistry, Cambridge, 1999, p. 202. 